\title{
THE AUREOMYCIN SENSITIVITY OF 100 PATHOGENIC STRAINS OF STAPHYLOCOCCUS AUREUS
}

\author{
BY \\ KEVIN ANDERSON \\ From the Department of Bacteriology, Guy's Hospital Medical School, London
}

(RECEIVED FOR PUBLICATION FEBRUARY 20, 1951)

Aureomycin, first described by Duggar (1948), has been used in the treatment of a wide range of bacterial infections. Staphylococcus has been listed as one of the more sensitive organisms, Bryer, Schoenbach, Chandler, Bliss, and Long (1948) finding that $0.6 \mu \mathrm{g} . / \mathrm{ml}$. was the smallest concentration of the antibiotic inhibiting growth in ordinary media. No figures were given for the number of strains tested, nor details relating to the source of these organisms. Evidence is available confirming the efficacy of this antibiotic in the treatment of staphylococcal bacteriaemia, especially in cases failing to respond to massive doses of penicillin (Ross, Burke, Rice, Schoenbach, Bischoff, and Washington, 1948). Localized skin infections have also responded to oral administration. It was decided, therefore, to investigate the aureomycin sensitivity of 100 pathogenic strains of Staph. aureus, obtained by culturing swabs from fresh septic lesions seen in the hospital casualty department.

\section{Methods for the Isolation of Suitable Strains}

One hundred and thirty-two swabs were examined in the course of this investigation. A short history accompanied each specimen, and only material from fresh septic lesions, seen for the first time in the casualty department, was accepted for culture. Swabs from patients already receiving antibiotics and from patients attending for daily dressings were discarded. On receipt in the laboratory, each swab was immediately inoculated on to three plates. One nutrient agar plate containing $5 \%$ sheep blood and one crystal violet horse blood agar plate (Garrod, 1933) were incubated aerobically. One 5\% horse blood agar plate was prepared for anaerobic incubation. All aerobic plates were read after overnight incubation at $37^{\circ} \mathrm{C}$. and again after standing for 24 hours at room temperature. Anaerobic plates were examined at the end of 48 hours' incubation. The number of colonies on the sheep blood plate was rarely less than 200 in the majority of swabs examined. Growth was frequently confluent at the site of primary inoculation and refractionation was occasionally necessary. The results of these preliminary investigations are set out in Table $I$.

Analysis of the information accompanying each specimen showed that the cases fell into the clinical categories enumerated in Table II.

One hundred organisms were selected from the first four groups after subjecting the strains to four accepted tests for pathogenicity.

1. Pigment Production.-The formation of pigment by strains of Staph. aureus was almost invariably apparent after overnight incubation at $37^{\circ} \mathrm{C}$. In doubtful cases, where scraping up growth with a wire loop failed to demonstrate golden colour, standing at 
TABLE I

Results of Culture of 132 Swabs

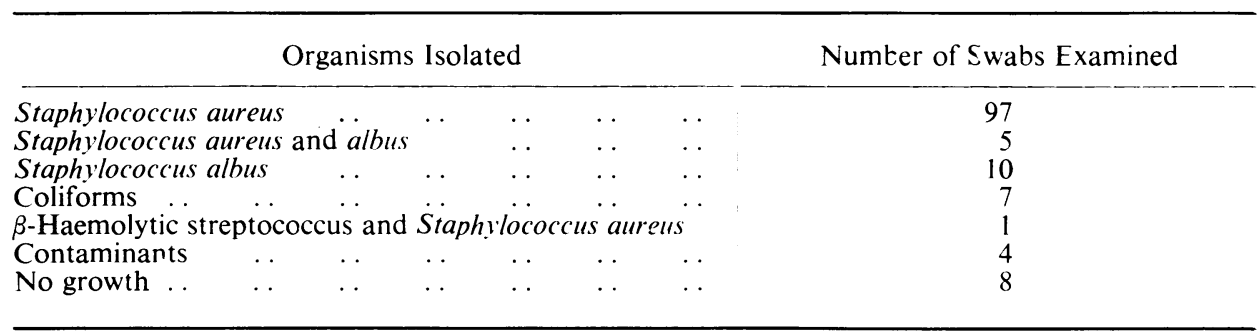

TABLE II

Clinical Classification of Swabs Examined

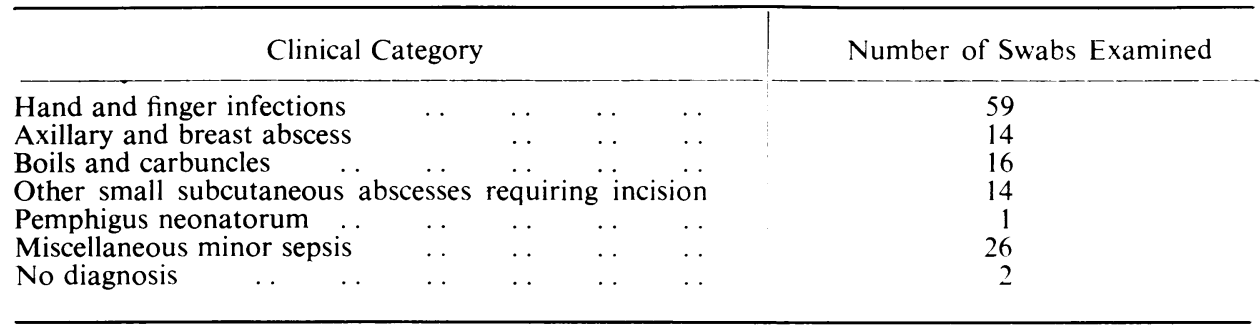

room temperature for 24 hours always enabled a definite decision to be made. All strains used in the sensitivity tests produced abundant colour under these conditions.

2. Coagulase Production.-Two techniques were used.

Slide Technique.--The method described by Cadness-Graves, Williams, Harper, and Miles (1943) was used throughout as a screening test, and was subsequently confirmed by the tube technique. It was rapidly and conveniently performed and gave clearly defined results which were, with one exception, in accordance with the tube coagulase tests. The exception was a heavily pigmented strain of Staph. aureus isolated from swab No. 57. This was repeatedly negative by the slide method, despite the use of several samples of fresh plasma. In the tube, a firm clot formed after 30 minutes' incubation, and this was repeated on two occasions. All other strains in the series reacted vigorously on the slide.

Tube Technique.-Fresh human plasma diluted 1 in 10 was incubated in $1 \mathrm{ml}$. amounts together with $0.1 \mathrm{ml}$. of a broth culture of the organism under test, according to the method described by Fisk (1940). Gillespie (1943) recommends a similar technique which differs but slightly from this. Tubes were incubated at $37^{\circ} \mathrm{C}$. and examined at hourly intervals for six hours. Many strains produced a firm clot whilst awaiting transfer to the incubator, and all those chosen for titration with aureomycin produced a clot in less than six hours.

3. Liquefaction of Gelatin.--It is generally accepted that the ability to liquefy gelatin cannot alone be taken as a reliable criterion of pathogenicity. Strains of Staph. albus frequently produce gelatinase, and in the course of examining 180 organisms Winslow, Rothberg, and Parson (1920) found that $47 \%$ of these reacted in this way. However, it is agreed that Staph. aureus liquefies gelatin more frequently and more rapidly than Staph. albus, and taken in conjunction with other tests, this property can be useful in the assessment of pathogenicity. 
In the present series, gelatin stab preparations were incubated at $25^{\circ} \mathrm{C}$. for five days. All selected strains produced saccate or infundibuliform liquefaction within this period. Organisms which failed to produce alteration in the medium after five days were discarded.

4. Fermentation of Mannitol.-Opinions differ widely regarding the value of biochemical activity in assessing the pathogenicity of staphylococci. As with the production of gelatinase, it is generally believed that Staph. aureus is more active and Staph. albus less so. Dudgeon and Simpson (1928) found that strains of Staph. aureus almost invariably fermented mannitol, whilst Staph. albus frequently did so. The rapidity with which mannitol is fermented by various strains has been employed in a method for grading pathogenicity (Knott and Blaikley, 1944). It was therefore decided to exclude all staphylococci which failed to ferment mannitol after overnight incubation at $37^{\circ} \mathrm{C}$. Many of the strains were seen to have fermented the sugar at the end of six hours.

Strains of Staph. aureus considered suitable as a result of the above tests were subcultured on to Dorset's egg medium and stored at room temperature after preliminary incubation.

\section{Preparation of Aureomycin Solutions}

Aureomycin hydrochloride was used throughout the investigation to prepare suitable solutions for sensitivity titrations. This substance is a yellow, crystalline solid, readily soluble in distilled water and to a less extent in saline. Owing to the high bulk-weight ratio, the salt can be easily weighed out in $1 \mathrm{mg}$. quantities on to a sterile watch-glass, using a micro-balance. Solutions of the salt in water have a $p \mathrm{H}$ of 4.5 . When made alkaline, these solutions rapidly lose antibacterial activity. It was clear, therefore, that normal liquid media, with an approximate $p \mathrm{H}$ of 7.4 , could not be used as solvents for the dry hydrochloride. Chandler and Bliss (1948) found that the rate of deterioration of aureomycin solutions was fairly constant for any given test organism. They maintained bacteriostasis during testing by adding fresh amounts of drug every 24 hours. As an alternative, it was decided to investigate the properties of solutions adjusted to a lower $p \mathrm{H}$ which would not inhibit the growth of the test organism. Staphylococci inoculated into glucose broth adjusted to levels below $p \mathrm{H} 6.0$ showed evidence of delayed growth when compared with cultures in normal broth. At $p \mathrm{H} 6.8$ growth was vigorous, and tryptic digest broth containing $0.25 \%$ dextrose was adjusted to this level for the initial experiments to determine the stability of aureomycin solutions.

Quantities, each of $1 \mathrm{mg}$. of aureomycin hydrochloride, were allowed to dissolve in one or two drops of glucose broth, then transferred by Pasteur pipette to $100 \mathrm{ml}$. of broth. The residue on the watch-glass was taken up with several more drops of broth and added to the container, thus giving a solution with a final concentration of $10 \mu \mathrm{g} . / \mathrm{ml}$. It was rather more yellow than normal broth, but the final $p \mathrm{H}$ was not altered from 6.8 by the addition of the antibiotic. Using $1 \mathrm{ml}$. as unit volume, doubling dilutions of this solution in glucose broth were made in 3 in. $\times \frac{1}{2}$ in. tubes, to a total of 10 tubes. One tube, containing glucose broth at $p \mathrm{H} 6.8$ without aureomycin, was included in each rack as a growth control. One strain of Staph. aureus, cultured from swab No. 106, was selected as a test organism. To each tube $0.02 \mathrm{ml}$. of a six-hour broth culture was added from a dropping pipette and the rack incubated at $37^{\circ} \mathrm{C}$. for 18 hours. At the end of this period, a reading was made by observing the presence or absence of diffuse, uniform turbidity. After a number of trials, it was found that the test organism was consistently inhibited by an apparent concentration of $0.625 \mu \mathrm{g} . / \mathrm{ml}$. The end-point was clear and well defined. However, it was obvious that the solution might have lost potency either whilst standing at room temperature for varying periods of time or during incubation at $37^{\circ} \mathrm{C}$. It was necessary, therefore, to examine solutions kept at room temperature. A container of $100 \mathrm{ml}$. of glucose broth containing $10 \mu \mathrm{g} . / \mathrm{ml}$. of aureo- 
mycin was left at room temperature $\left(21^{\circ} \mathrm{C}\right.$.) and samples withdrawn at hourly intervals for a total of six hours. Each sample was titrated with strain 106 and transferred to the incubator immediately afterwards. It will be seen from Fig. 1 that the total age of each sample was 24 hours, compounded at varying times at $21^{\circ} \mathrm{C}$. and $37^{\circ} \mathrm{C}$. The first sample was titrated at once and was incubated for 24 hours at $37^{\circ} \mathrm{C}$. The final sample remained at room temperature for six hours and was incubated for 18 hours. All racks were read the following morning and no variation from the previous recording of $0.625 \mu \mathrm{g} . / \mathrm{ml}$. was observed.

A further $100 \mathrm{ml}$. of aureomycin solution of similar strength was prepared and divided into two $50-\mathrm{ml}$. quantities. One portion was left at room temperature $\left(21^{\circ} \mathrm{C}\right.$. $)$ for a total of six hours, and titrated at hourly intervals as before. The other $50 \mathrm{ml}$. quantity was placed in the incubator at $37^{\circ} \mathrm{C}$. for the same period, and also titrated hourly. The results were similar to those shown in Fig. 1. The observed sensitivity of strain 106 showed no variation from $0.625 \mu \mathrm{g} . / \mathrm{ml}$. in either sample. It was therefore considered that aureomycin solutions prepared in this manner possessed sufficient stability to warrant their use in the proposed sensitivity tests. At present, little is known of the way in which aureomycin produces its effect in vivo and in vitro. In the course of bacteriological studies, Price, Randall, and Welch (1948) noted a marked variation between the bacteriostatic and bactericidal end-point. However, they recorded the fact that destruction of the aureomycin was doubtless occurring during the incubation period, since they were using solutions at $p \mathrm{H} 7.0$ and above. They found that various media ingredients caused marked destruction, and that thioglycollate medium tended to preserve the potency of the aureomycin to a greater degree than other media used. In the present series it would appear that, for the staphyloccoccus strain 106, aureomycin solutions at $p \mathrm{H} 6.8$ retain those properties which enable consistent in vitro readings to be made. Whether sensitivities so obtained bear any relationship to the effective bloodlevel during treatment of staphylococcal infections is a matter for additional investigation. Furthermore, it is not yet determined whether this method of testing sensitivity is applicable to other organisms.

\section{Sensitivity Testing of Pathogenic Strains}

Titrations were carried out in the manner described, 12 strains being tested each day. Organisms were transferred from Dorset egg slopes into $5 \mathrm{ml}$. quantities of nutrient broth. Subculture from broth on to segments of blood agar plates was made in every case to chesk purity. Racks were read after 18 hours' incubation at $37^{\circ} \mathrm{C}$.

\section{Results}

Fig. 2 analyses the results of 100 strains tested under these conditions. It will be seen that 81 organisms were sensitive to $0.625 \mu \mathrm{g} . / \mathrm{ml}$. of aureomycin or below. Nineteen strains were inhibited by $1.25 \mu \mathrm{g} . / \mathrm{ml}$. The lowest effective concentration in the series was $0.078 \mu \mathrm{g}$. $/ \mathrm{ml}$.

\section{Summary}

One hundred pathogenic strains of Staph. aureus were isolated from fresh septic lesions seen in the hospital casualty department.

A method is described for the preparation of aureomycin solutions which appear to possess considerable stability when titrated with strains of Staph. aureus.

The aureomycin sensitivity of the collected strains, determined by this technique, is recorded. 


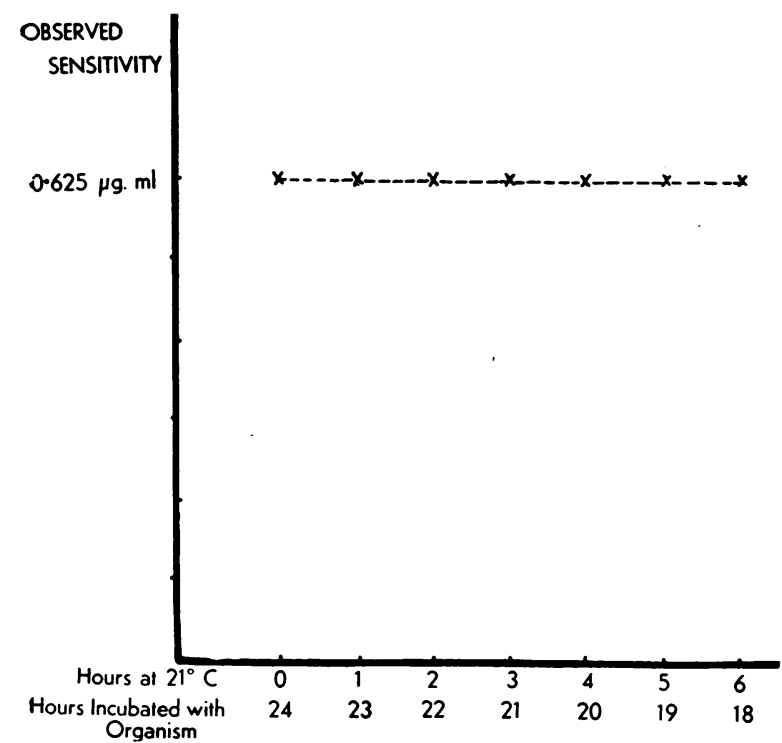

FIG. 1.-Titration of aureomycin hydrochloride solution kept at room temperature $\left(21^{\circ} \mathrm{C}\right.$.) for six hours.

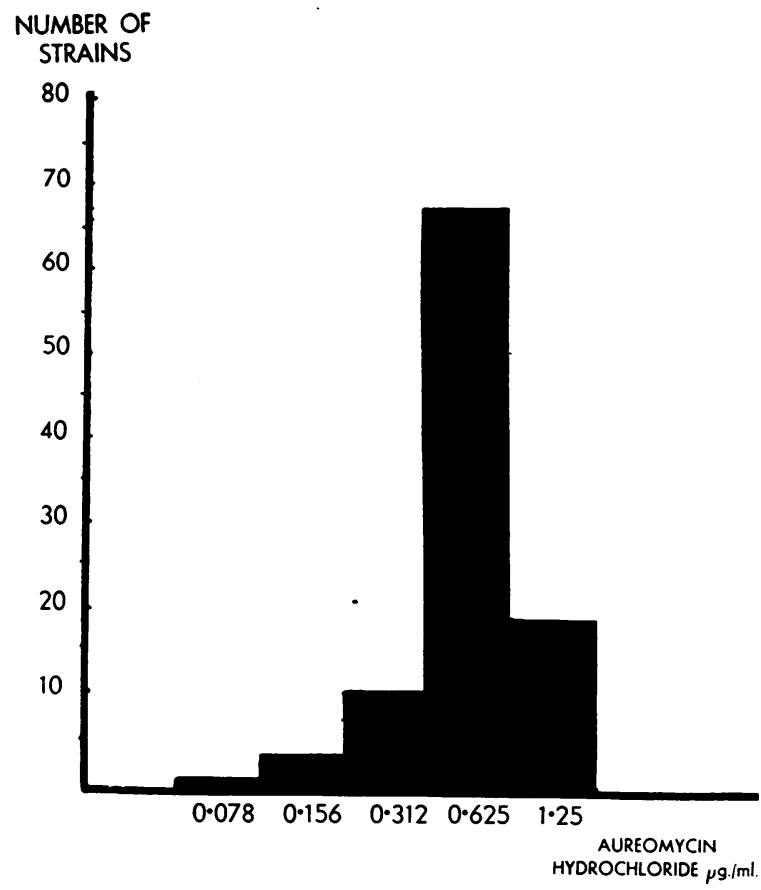

FIG. 2.-Distribution of sensitivity of 100 strains of Staph. aure..s to aureomycin hydrochloride.

I am indebted to Professor R. Knox for his advice and encouragement during the preparation of this paper ; to Mr. Patrick Clarkson for permission to collect material from the Casualty Department, and to the Department of Medicine, Guy's Hospital, for supplies of aureomycin hydrochloride. My thanks are also due to the casualty officers on duty for their co-operation in obtaining the material for this investigation.

\section{REFERENCES}

Bryer, M. S., Schoenbach, E. B., Chandler, C. A., Bliss, E. A., and Long, P. H. (1948). J. Amer. med. Ass., 138, 117.

Cadness-Graves, B., Williams, R., Harper, G. J., and Miles, A. A. (1943). Lc.ncct, 1, 736.

Chandler, C. A., and Bliss, E. A. (1948). Ann. N.Y. Acad. Sci., 51, 221.

Dudgeon, L. S., and Simpson, J. W. H. (1928). J. Hyg., Camb., 27, 160.

Duggar, B. M. (1948). Ann. N.Y. Acad. S i., 51, 177.

Fisk, A. (1940). Brit. J. exp. Path., 21, 311.

Garrod, L. P. (1933). St. Bart's Hosp. Rep., 66, 203.

Gillespie, E. H. (1943). Mon. Bull. Min. H.th, 2, 19.

Knott, F. A., and Blaikley, J. B. (1944). J. Obst?t. Gynaec. Brit. Emp., 51, 386.

Price, C. W., Randall, W. A., and Welch, H. (1948). Ann. N.Y. Accd. Sci., 51, 211.

Ross, S., Burke, F. G., Rice, E. C., Schoenbach, E. B., Bischoff, H., and Washington, J. A. (1948). Clin. Proc. Child. Hosp., Wash., 4, 315.

Winslow, C.-E. A., Rothberg, W., and Parsons, E. I. (1920). J. Bact., 5, 145. 